\title{
A secreta partitura das imagens: M emórias das múltiplas moradas de um castelo interior
}

\author{
Miguel-Pedro Quadrio
}

O deserto que intitula a peça [Desertos] é essa paisagem vazia atravessada pela humanidade nómada que sobra da memória europeia.

Fernando Matos Oliveira (2003: 89)

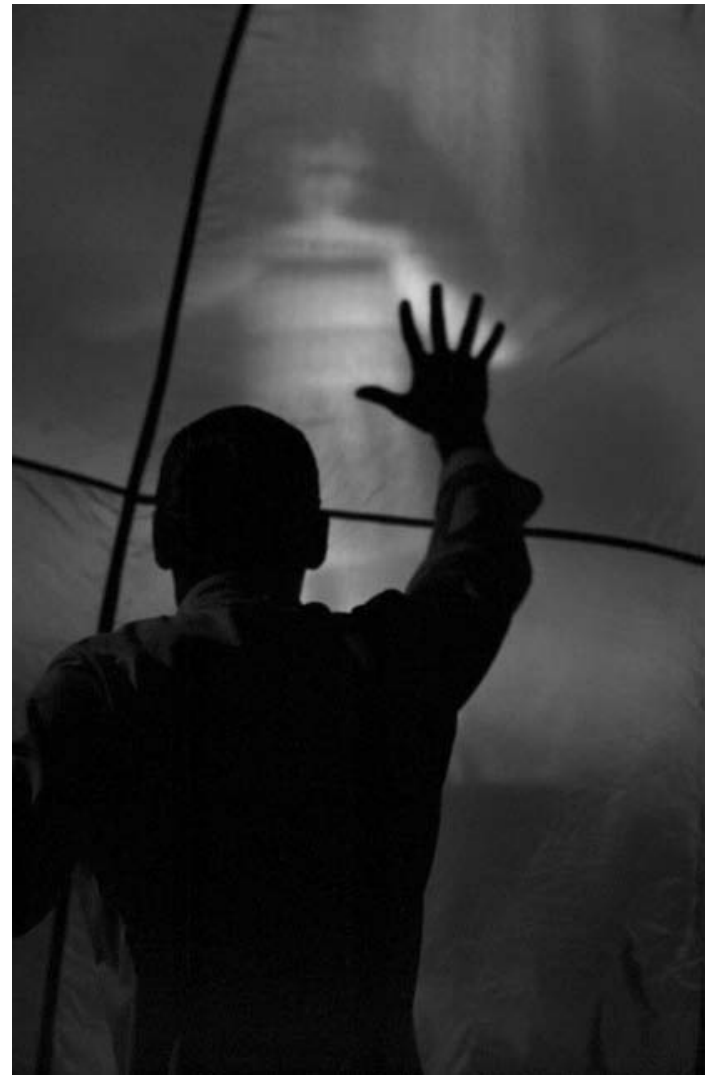

\section{Introdução}

Em Callas Forever - desmesurada e bizarra fantasia cinematográfica em torno duma imaginária interrupção da reclusão parisiense de Maria Callas -, o realizador Franco Zeffirelli ajusta subtilmente contas com os críticos, através da personagem duma simpática e idosa crítica musical, espécie de versão sofisticada (não muito...) da Miss Marple de Agatha Christie. É de tal modo convincente (e comovente) o altruismo generoso e franco com que esta personagem ajuda Callas a emergir do torpor depressivo em que a tinham lançado a perda de Onassis e da voz, que qualquer espectador de boa vontade tomará por profunda e sincera confissão o desabafo, que a dada

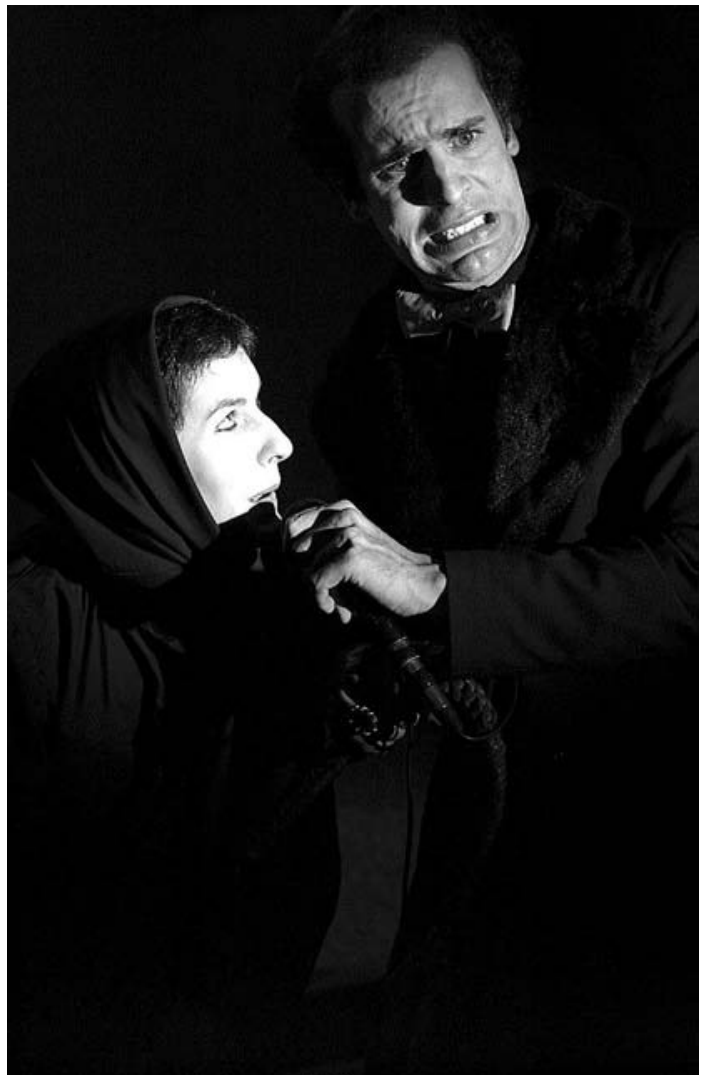

altura, partilha com a diva: "... o vampiro sou eu. Sou uma jornalista, lembra-se? Nós chupamos o sangue porque, como é evidente, não sabemos cantar, nem dançar, nem pintar, nem fazer nada". Vi o filme quando preparava este texto. Primeiro suspirei de alívio, porque a desbocada old lady não se lembrara do teatro; mas depois - reflectindo melhor e talvez porque nesse dia fosse eu o tal espectador ingénuo - reconheci que me convinha especialmente hoje esse lugar duma inutilidade vazia, mais que não fosse porque a quem não sabe fazer nada, não poderá quem canta, dança, pinta ou... representa exigir mais do que algumas bagatelas inúteis de fim de tarde. Cá vão elas então. 


\section{Despojos}

Antes de iniciar a reflexão sobre o Circo - e já que a entrega desta Menção Especial ocorre em 2004, ano em que o Teatro da Garagem comemora o seu décimo quinto ano de existência - recordo, de Quadros de uma exposição (projecto que inaugura a comemoração do acontecimento), a primeira imagem com que, no piso térreo do actual espaço do colectivo (em Lisboa, no Poço do Bispo), o encenador Carlos J. Pessoa confrontava o espectador: "...uma ordenação desordenada de despojos cenográficos de produções anteriores" (Quadrio 2004). Na crítica que fiz ao espectáculo, designei genericamente por despojos esta assunção e recuperação da memória, para conciliar duas leituras possiveis: a daqueles que os entendessem como amontoado informe de objectos privados de significação - fosse por se encontrarem descontextualizados, fosse por desconhecimento dos espectáculos em que haviam sido utilizados - com a dos que neles vissem a tradução dramatúrgica da valorização que, em ano de celebração dum percurso já longo, o Teatro da Garagem atribuía ao seu espólio. Independentemente, porém, do significado que se atribua a essa exibição fragmentária ${ }^{4}$ o regresso ao passado ai proposto pelo grupo cauciona que, também eu, regresse aos despojos dalguma crítica para tentar entender como (uma parte d') o público recebeu o trabalho do Teatro da Garagem.

\section{Gerações e discursos}

A mais ampla caracterização sócio-estética do trabalho do Teatro da Garagem encontra-se no artigo "Conversação \&t colagem" de Fernando Matos Oliveira, republicado em 2003 na colectânea de ensaios Teatralidades: 12 percursos pelo território do espectáculo, numa edição revista dum texto que, no n. 6 da revista virtual Ciberkiosk (Julho de 1999), apresentava criticamente Desertos: Evento didáctico seguido de um poema grátis, peça que recebera o Prémio Ciberkiosk de 1998. Vale a pena relembrá-la, ainda que reduzida a uma esquematização empobrecedora, pela clareza e precisão com que nela se traçam algumas das linhas que teceram o percurso do Teatro da Garagem. Valerá a pena também, ainda que sumariamente, cruzá-la com outras vozes da crítica:

a) caracterização social e política - o aparecimento do Teatro da Garagem em 1990 - com o espectáculo Pequeno areal junto à falésia com cravos, parece-me - dá-se no trânsito de gerações do teatro independente, o qual distingue a geração que viveu o final da ditadura e a aventura políticorevolucionária do PREC - identificada, como veremos, com um carácter matricial e utópico - e que, nos anos 90, se encontra consolidada: "as décadas de oitenta e noventa coincidiram com a consagração dos grupos maiores, como o Bando, a Cornucópia, o TEC, a Comuna, entre outros" e apta - nas suas convulsões, acrescentaria eu - a originar "estruturas produtivas polivalentes" como o CENDREV, os Artistas Unidos e o AMASCULTURA (cf. Oliveira 1993: 8586). Numa identificação muito genérica desta geração,

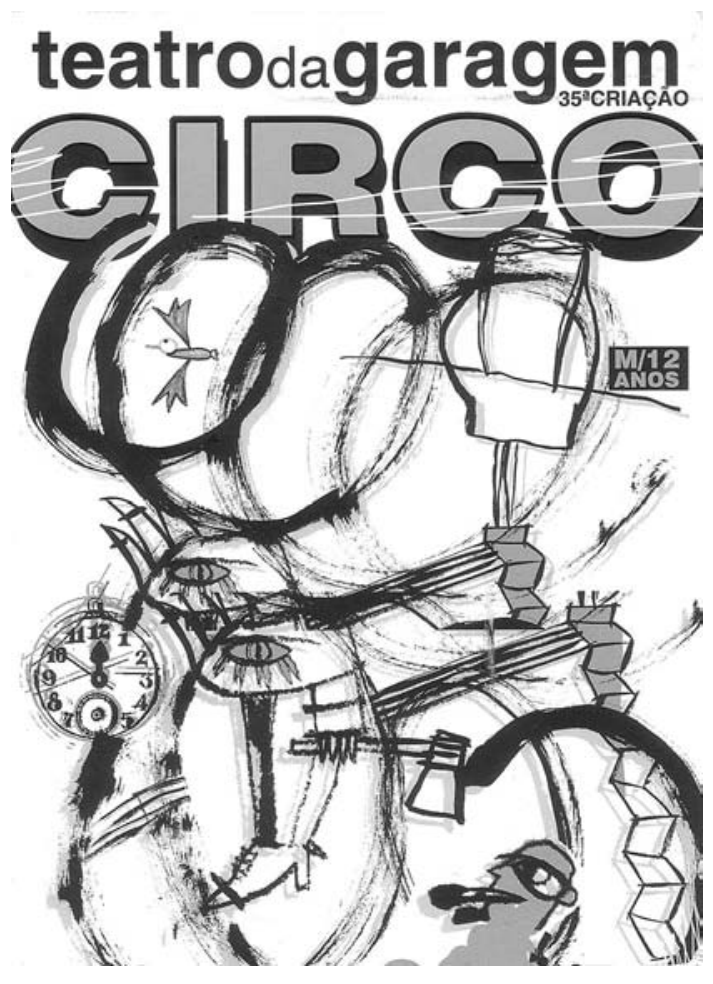

Matos Oliveira recorre a uma afirmação de Jorge Silva Melo sobre os anos sessenta europeus - "A Cultura do Homem Bom não sabia resistir à fúria de absoluto que a súbita riqueza da juventude dos anos 60 agora exigia" (apud Oliveira 2003: 87; Melo 1998: 300) - para caracterizar os anos noventa portugueses, desfasamento que se torna particularmente pertinente se pensarmos que a ditadura impediu Portugal de acompanhar o desenvolvimento da Europa do pós-guerra e que a abertura revolucionária e a adesão, em 1986, à então Comunidade Económica Europeia desencadearam uma recepção heteróclita de novidades de última hora e outras, tomadas como tal, que já tinham uma patine de trinta anos. Concluiu Matos Oliveira: "A versão portuguesa mais próxima desse Homem seria talvez a do periodo pós-74" (2003: 87). ${ }^{5}$

Distingue esta primeira geração, dizia, daquela(s) nova(s) geração(ões) que, emergindo nos anos 90, têm "por detrás uma materialidade histórica intimamente ligada ao aprofundamento da integração europeia e à participação de um número cada vez mais vasto de portugueses no devir consumista do cidadão global" (Oliveira 2003: 86-87) e que portanto - regressando à acomodação que Matos Oliveira faz da citação de Silva Melo - integram um tempo português que parece mimar "a saturação europeia de sessenta, obviamente com aquele grau de distorção que é devido à repetição dos factos históricos: primeiro como tragédia, depois como comédia" (Oliveira 2003: 87); ${ }^{6}$

b) caracterização institucional - a "emergência dos novos" coincide com uma política de descentralização e
${ }^{3}$ "Antes que se inicie o

espectáculo, o público da $36^{a}$ produção do Teatro da Garagem, a que abre a comemoração dos quinze anos de vida do grupo, é recebido no andar térreo do espaço do Poço do Bispo, podendo deambular por entre uma ordenação desordenada de despojos cenográficos de produções anteriores" (Quadrio 2004)

${ }^{4}$ Que poderia ser completada pelo número já razoável de edições de textos dramáticos de Carlos J. Pessoa (Cidade de Fausto, Café magnético Pentateuco: Manual de sobrevivência para o ano 2000 e A portageira da brisa) e, deveria sê-lo, por uma publicação onde, de forma alargada, o Teatro da Garagem fixasse um dos espólios mais significativos da segunda geração do teatro independente português.

${ }^{5}$ Estranho, neste primeiro bloco, as ausências do Grupo de Teatro de Campolide, hoje Companhia de Teatro de Almada (e do seu fundador Joaquim Benite), do Grupo 4/Novo Grupo (e de João Lourenço e Irene Cruz, primeiro e, mais tarde, de Vera San Payo de Lemos) eda dupla Ricardo Pais/António Lagarto.

\section{${ }^{6}$ Eugénia Vasques, na} resenha "Efemérides teatrais: Pequena cronologia", que incluiu no catálogo da exposição Fragmentos da memória: Teatro independente em Portugal (1974-1994), limita-se a registar no ano de 1989 a "formação, em Lisboa, da companhia Teatro do Tejo e do grupo Teatro da Garagem" (Vasques 1994b: 90). 
<< (pág. anterior) Ilustração Paulo Cardoso.

7 Esta situação surgia

realçada no lead da panorâmica sobre o teatro que se podia ver em Lisboa, publicada em 2003 por um jornalista inglês nas páginas do The Guardian: " $\mathrm{Na}$ primeira de uma nova série sobre o teatro europeu, John O'Mahony visita Lisboa e encontra um cenário em crescimento sem edificios,

dinheiro - nem espectadores" (0'Mahony 2003, tradução minha).

${ }^{8}$ Relembre-se que, só em 2002, conseguiu o Teatro da Garagem responsabilizar-se por um espaço próprio - o actual Espaço do Teatro da Garagem, ao Poço do Bispo -, apesar da distância do

centro de Lisboa e da dificuldade de acessos serem claros obstáculos à presença

de muitos dos seus potenciais espectadores. com a abertura de novos espaços de representação factores que a favorecem - ainda que, reclamando o mesmo modelo de financiamento da primeira geração, se encontrem igualmente dependentes da "oscilação endémica da política cultural" (Cf. Oliveira 2003: 85). Ora a vertente institucional não remeterá apenas para as deficiências impostas, extrinsecamente, pela conjugação infeliz entre um financiamento errante e uma não menos incompreensivel intermitência na fixação do(s) público(s), embora esta última oscilação ${ }^{7}$, conjugada com as dificuldades financeira que hipotecam a programação a médio prazo e a manutenção de espaços condignos de representação, sejam factores de desgaste e, até, de extinção dalguns grupos. ${ }^{8}$. Há ainda a considerar a organização interna dos novos grupos que, no caso concreto do Teatro da Garagem e segundo as formulações subtilmente críticas de Carlos Porto (1994: 13) e de João Carneiro (1999: 74), repetiria o modelo da primeira geração do teatro independente, o qual se materializara em "estruturas orientadas (dominadas?) por determinados criadores". Esta repetição torná-los-ia segundo João Carneiro - num "exemplo acabado da institucionalização do novo: uma companhia com um núcleo fixo mínimo, com um dramaturgo - escritor permanente [Carlos J. Pessoa], também encenador, com uma actividade regular e um estilo próprio".

c) caracterização ética e estética - integrando-se numa "geração individualista e dispersa [de subúrbio] a que faltaram as referências dos seus ascendentes imediatos" (Oliveira 2003: 87) - Matos Oliveira sustenta esta inscrição numa "existência intervalar" resumindo um texto de Carlos J. Pessoa: "nasceram em finais da década de sessenta: tarde de mais para a vivência adulta da Revolução, mas justamente a tempo para dela terem uma memória vaga": "Terá sido precisamente o desacerto social e histórico do subúrbio (...) que conduziu o projecto do Teatro da Garagem à 'reflexão sobre uma jovem democracia num país velho de oito séculos', mantendo sempre nesse pensamento 'o espírito da garagem às costas'" (Oliveira 2003: 89). Teriamos, então, por um lado, o comprometimento vago de Abril, aliado ao inconformismo do subúrbio, expressando-se num zapping pós-moderno de formas que organizariam um território pós dramático e cuja dramaturgia seria balizada pela reciclagem de matéria formal disponibilizada pela tradição e pelo "oportunismo dramatúrgico pós-moderno" (cf. Oliveira 2003: 87-88, citando Sarrazac 2002: 235).

Quando a tradição é omissa - refiro-me à excessiva dependência externa no campo da escrita dramática que a primeira geração do teatro independente instituíra Matos Oliveira considera que a nova geração ou seguiu a tendência da anterior ou, nos casos em que tentou contrariála, optou por reequacionar o lugar do texto quer num teatro entendido como evento celebratório ou choque cruel (exemplifica com os nomes de Lúcia Sigalho, Luís Castro e João Garcia Miguel), quer - e seria este o posicionamento do Teatro da Garagem que na maioria das suas criações utilizou peças novas de Carlos J. Pessoa - num teatro que se mantém como transposição medial de um texto, centro crítico da prática teatral (cf. Oliveira 2003: 86).

Sobre a tensão que parece causar na crítica a dupla condição de dramaturgo e encenador de Carlos J. Pessoa, vale a pena avançar com três notas complementares.

Nota 1: No catálogo a que já aludi - publicado quatro anos depois da formação do Teatro da Garagem -, Vasques (1994a: 39), na breve sintese histórica sobre o teatro pós25 de Abril, refere-se uma só vez a Carlos J. Pessoa, contando-o entre os novos autores portugueses. Esta preferência pelo dramaturgo em detrimento do encenador parece confirmada pela curiosidade de, num trabalho profusamente ilustrado com fotografias de quase todo o tecido teatral português de então, não constar uma única imagem dum espectáculo do Teatro da Garagem.

Nota 2: Não sei até que ponto estas duas linhagens artísticas definidas por Matos Oliveira não provirão, antes, da tensão no interior da primeira geração do teatro independente, a qual é situada nos anos 80 por Eugénia Vasques: "foi só passado quase dez anos sobre a revolução de Abril que as chamadas 'novas linguagens', introduzidas desde cedo, pelo Teatro da Cornucópia ou, entre outros, por Ricardo Pais, Osório Mateus, Carlos Zíngaro ou Constança Capedeville, começaram a ganhar terreno no teatro português", transitando-se, então, dum teatro "que tinha, genericamente, como utopia 'a educação' para um teatro consciente da pulverização de públicos, da fragmentação da comunicação, da desarticulação de nexo entre forma e sentido, com o consequente investimento em formas mais imagéticas do que intelectuais ou em dramaturgias menos dialécticas do que metafóricas" (Vasques 1994a: 27).

Nota 3: Na mesma linha de Matos Oliveira, João Carneiro classifica de hibridos os textos de Carlos J. Pessoa, pois neles «se misturava, senão tudo, pelo menos muita coisa: poesia, narrativa, especulação filosófica, referências ao nosso quotidiano, a um fundo cultural conhecido. A história do bairro passou a coexistir com a história da cidade ou com a história dos descobrimentos, o merceeiro da esquina com Maria Callas; também neles regista o convivio dum registo sério com "o irónico e o humorístico", concluindo dum modo que me parece especialmente relevante: o recurso ao fragmento não decorreria dum efeito estilistico do texto ou a dum superficial e passageiro maneirismo estetizante, mas da estruturação cultural em que se funda a prática dramatúrgica do Teatro da Garagem. Esta escolha desligará o espectador duma noção transitiva de sentido - que inevitavelmente o faria esbarrar na vulgar discussão em torno da bizarria, originalidade ou desvio da proposta teatral - desafiando-o, antes, para uma (re)projecção contemporânea, sem antecedentes em Portugal, dos elementos que desde sempre justificaram a prática teatral - e volto ao texto de João Carneiro "o público, o actor, a personagem e o espaço; a vista e o ouvido; e, mesmo ainda, a surpresa e o prazer do espectáculo" (Carneiro 1999: 74). 


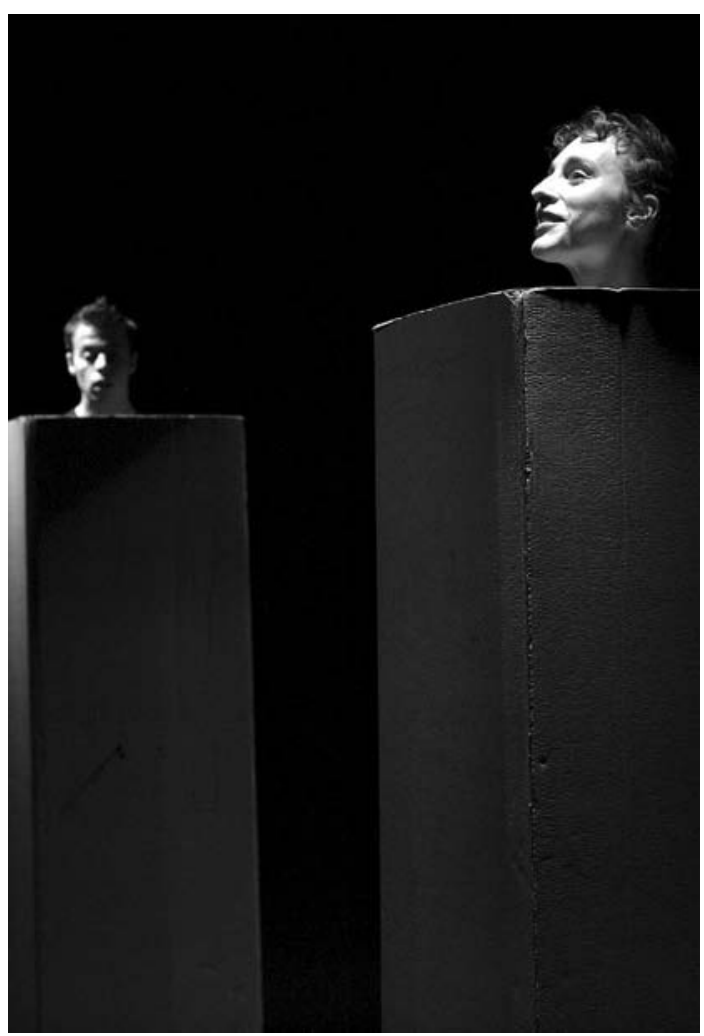

\section{Finalmente, o Circo}

Glosando mais uma vez o trabalho de Matos Oliveira, reconheço que já vai longa esta conversação e que muita foi a colagem às palavras de outros. Confesso, no entanto, que me foi particularmente grato rever, nos pontos de vista expressos por quatro respeitados investigadores e críticos teatrais - Fernando Matos Oliveira, Eugénia Vasques, Carlos Porto e João Carneiro -, alguns dos pressupostos teóricos e juizos estéticos que desenvolvi nas reflexões acerca dos espectáculos do Teatro da Garagem que publiquei no Diário de Notícias. Esta coincidência nas análises, não me torna insensivel, porém, à diferente valorização crítica de que têm sido alvo os mais recentes produtos que saíram da fábrica teatral da Garagem. Não me esqueço ainda do modo incisivo como, na crítica a Quadros de uma exposição, destaquei este colectivo no contexto da segunda geração do teatro independente português - sublinhando a "intervenção cívica e ética do grupo [como] a mais bem resolvida expressão do nosso pós-modernismo teatral" (Quadrio 2004) -, e dos remates encomiásticos que dediquei às três produções de 2003: Paixão segundo o meu anjo "Trata-se assim dum espectáculo belo, difícil, imperfeito, já que não é fácil forçar os deuses a mostrarem a razão que o seu rosto esconde" (Quadrio 2003c) -, Adélia Z "esta reafirmação do actor como catalisador insubstituível à comunicação teatral encontrou no lirismo e na marginalidade da Adélia de Maria João Vicente uma comovente validação" (Quadrio 2003b) - e Circo - "julgo que a terceira e conclusiva etapa tem lugar no $2^{\circ}$ andar do teatro para fisicamente assinalar ao espectador que a clareza do discurso ouvido, a serenidade do humor e a subversiva capacidade de auto-ironia correspondem à celebração festiva duma vontade artística [...], à consagração da nova sala e à demarcação dum ponto de chegada..." (Quadrio 2003a).

Ora só mais tarde, quando escrevi sobre Quadros de

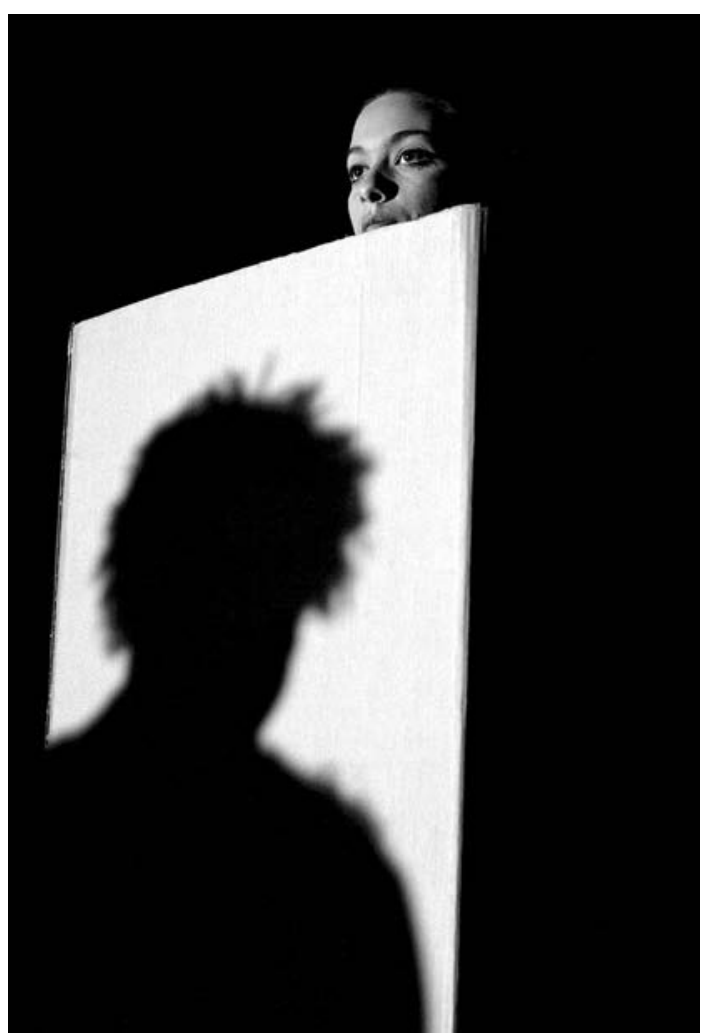

Circo

enc. Carlos J. Pessoa,

Teatro da Garagem, 2003

(Tiago Mateus e

Carina Cardoso;

Susana Andrade),

fot. Susana Paiva. uma exposição, consegui objectivar esta percepção de que, em Circo, aquilo que venho designando (e caracterizando) como percurso do Teatro da Garagem adquirira uma

maturidade onde já se resolvera a mistura heteróclita a que se referia João Carneiro - e cito - "Martelar mais as teorias não é aqui indispensável, pois Quadros de uma exposição é a mais iluminadora sintese do projecto da Garagem. A evidência do confronto geracional na oposição do Sujeito em estado de coma (Miguel Mendes, actor que vem assumindo em cena a voz autoral de Pessoa, é o autor/encenador dum grupo também moribundo) e da Condessa (Maria João Vicente, co-fundadora do colectivo, interpreta a empresária falida) à Actriz (Ana Palma,

exuberantemente caprichosa) e a Lenny (Fernando Nobre, o menino selvagem ou o redentor?); a acutilância duma reflexão sobre o teatro, quando o modo de conhecimento cede à prática industrial (aproximação de Handke e, sobretudo, do prolixo pessimismo de Bernhard); a surpresa dum quase pudor na encenação de texto alheio (a contida manipulação da Pentesileia de Kleist antecipa a abertura a reportório que não de Pessoa?)" (Quadrio 2004).

Nesse espectáculo eram observáveis as mesmas marcas textuais e cénicas a que venho aludindo e que agora resumo. Primeiro, a intermitência textual - assinalada pela colagem, histórica e literariamente descontextualizada, de discursos; pelas constantes interferências fragmentárias doutras vozes; pela sucessão de falas numa espécie de dialogismo monologado; pela metamorfose fluida das personagens; pela alegorização inesperada de personagens tipo). Depois, a deriva espacial e genológica - o espectador de Circo é sujeito a um percurso físico em três etapas - a rua, o espaço do rés-do-chão e a sala do $1^{\circ}$ andar - que é simultaneamente um périplo pela farsa circense dum teatro que desce à rua para granjear o seu público; pela tragédia - e recordo o que então escrevi: "a segunda etapa (...) é a via purgativa do circo propriamente dito, com as suas rápidas e cruéis 
Adélia Z, enc. Carlos J. Pessoa,

Teatro da Garagem, 2003 (Maria João Vicente), fot. Susana Paiva. desfigurações morais (o inteligente e tortuoso humor cáustico de Pessoa estilhaça e reinventa os tipos expectáveis equilibristas, domadores de feras, contorcionistas, palhaços, trapezistas - em fragmentos de vozes que, não chegando a definir personagens, são apenas mais um elemento que integrará a sucessiva acumulação de poderosas imagens). (...) neste segundo momento se reconhecem as inquietações que afectaram os (...) anteriores trabalhos do grupo (...) Paixão segundo o meu anjo e Adélia Z)" (Quadrio 2003a); - e pela comédia lírica. Por último, estética genuinamente pós-moderna caucionada pelo rigor e expressividade com que fundem o entrelaçamento discursivo, a recomposição visual de objectos e signos improváveis e um trabalho de actor que, com um surpreendente à-vontade, manipula os vários códigos de representação do século XX.

Ora, o que me parece ter acontecido de novo naquele segundo andar dum barracão do Poço do Bispo, quando aí se representava o Circo, foi a transmutação de um vórtice fragmentário - expressão onde faço a síntese possivel de tudo o que já disse - numa unificada vertigem de imagens. A deslocação da recepção da sintaxe para a (sua) capacidade de expandir associações só foi possível face a três mudanças significativas: uma depuração textual; a acentuação duma religiosidade panteísta que parece traduzir-se na vontade de estabelecer com o espectador uma comunidade discursiva livre, onde a constante reformulação de sentidos, que a sociedade contemporânea impõe, é sujeita a um ritual teatral de experimentação e validação partilhada; e - elemento fundamental - a crescente preponderância do elemento musical que, na sua evanescência linguistica e dada a qualidade que Daniel Cervantes the tem imprimido, potencializa e reunifica a tão propalada dispersão da Garagem. Ou dito de outra forma: "o que aqui se torna deslumbrantemente belo e comovente é a incandescente mestria com que, encenador e actores fundem todos os discursos (...) numa ondulante vertigem de imagens (...). Esta culta partilha de 'afinidades electivas', [devolve] ao teatro uma comunicabilidade de que parecia arredado" (Quadrio 2003a).

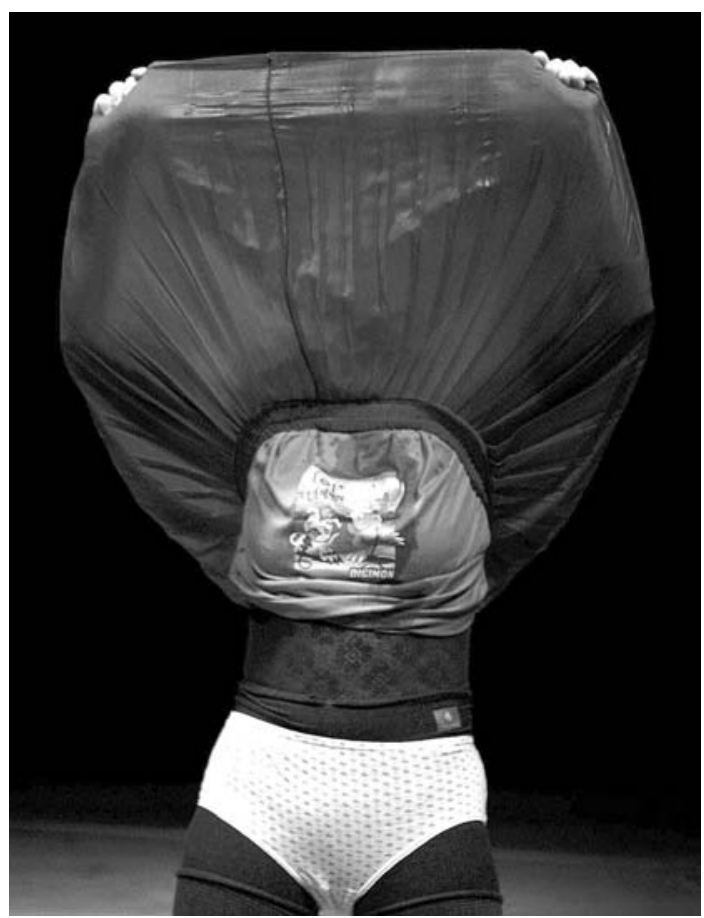

Referências bibliográficas

CARNEIRO, João (1999), "Dramaturgias nacionais", Teatro escritos: Revista de ensaio e ficção, Lisboa, IPAE e Cotovia, nº 2, pp. 73-76.

OLIVEIRA, Fernando Matos (2003), "Conversação \&t Colagem", Teatralidades: 12 percursos pelo território do espectáculo, Lisboa, Angelus Novus, pp. 85-96.

MELO, Jorge Silva (1998), "Teatro para os novos, religião dos novos papas", in AA. W., Essas outras histórias que há para contar, Lisboa, Edições Salamandra, pp. 298-308.

O'MAHONY, John (2003), "The Big Experiment", The Guardian, 13 de Setembro. PORTO, Carlos (1994), "Memória de fragmentos", in Eugénia Vasques et al.

(ed.), Fragmentos da memória: Teatro independente em Portugal (19741994), Catálogo da exposição realizada no âmbito dos Encontros ACARTE 1994, Lisboa, Acarte/F.C.G., pp. 7-25.

QUADRIO, Miguel-Pedro (2003a), "As moradas do castelo interior" (critica de teatro a Circo, Teatro da Garagem, encenação de Carlos J. Pessoa, estreia 17 de Julho), Diário de Notícias, 5 de Agosto.

- - (2003b), "O regresso de Adélia Z" (critica de teatro a Adélia Z, Teatro da Garagem, encenação de Carlos J. Pessoa, estreia 13 de Fevereiro), Diário de Notícias, 19 de Fevereiro.

- - (2003c), "Se numa noite de Inverno um anjo" (crítica de teatro a Paixão Segundo o Meu Anjo, Teatro da Garagem, encenação de Carlos J. Pessoa, estreia 20 de Dezembro), Diário de Notícias, 20 de Janeiro.

- - (2004), "Paisagem com uma condessa ao fundo" (critica de teatro a Quadros de uma exposição, Teatro da Garagem, encenação de Carlos J. Pessoa) Diário de Notícias, 29 de Janeiro.

VASOUES, Eugénia (1994a) "Cometimentos / Sofrimentos: 13 fragmentos", in Eugénia Vasques et al. (ed.), Fragmentos da memória: Teatro independente em Portugal (1974-1994), Catálogo da exposição realizada no âmbito dos Encontros ACARTE 1994, Lisboa, Acarte/F.C.G., pp. 2741.

- - (1994b), "Efemérides teatrais: Pequena cronologia", in Eugénia Vasques et al. (ed.), Fragmentos da memória: Teatro independente em Portugal (1974-1994), Catálogo da exposição realizada no âmbito dos Encontros ACARTE 1994, Lisboa, Acarte/F.C.G., pp. 88-91.

SARRAZAC, Jean-Pierre (2002), o futuro do drama, trad. Alexandra Moreira da Silva, Cadernos Dramat no. 9, Porto, Campo das Letras. 